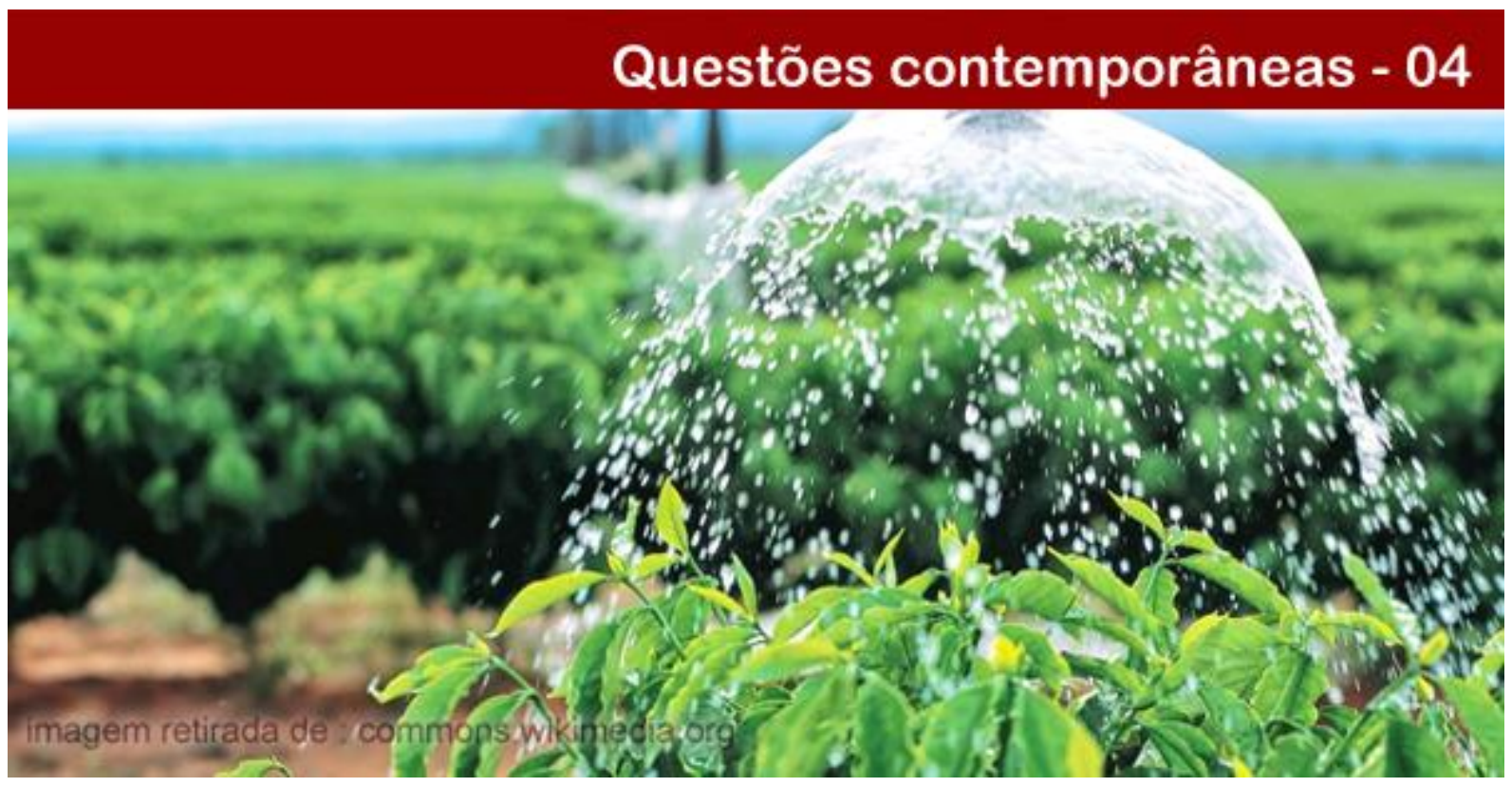

\title{
SUSTENTABILIDADE DE PRODUÇÃO AGRÍCOLA DAS FAMÍLIAS ASSISTIDAS PELO PROJETO DE TRANSPOSIÇÃO DO RIO SÃO FRANCISCO EM SÃO JOSÉ DE PIRANHAS - PB
}

Flávia Clessione Cordeiro da Cruz

Graduada em Ciências Biológicas pela Universidade Federal de Campina Grande (UFCG). E-mail: flaviaclessione@gmail.com.

\section{José Deomar de Souza Barros}

Licenciado em Ciências com habilitação em Biologia e em Química pela Universidade Federal de Campina Grande (UFCG). Especialista em Agroecologia pela Universidade Federal da Paraíba (UFPB). Especialista em Ensino de Química pela Universidade Regional do Cariri (URCA). Mestre e Doutor em Recursos Naturais pela UFCG. Professor Adjunto da Universidade Federal de Campina Grande (UFCG). Coordenador do Grupo de Pesquisa Ambiental para o Desenvolvimento do Semiárido.E-mail: deomarbarros@gmail.com.

Francisca Soares de Sousa

Graduada em Serviço Social pela Faculdade de Filosofia, Ciências e Letras de Cajazeiras (FAFIC). E-mail: sfrancisoares@yahoo.com.br.

\section{André Lima Leite}

Graduado em Ciências Biológicas pela Universidade Federal de Campina Grande (UFCG). E-mail: andresjppb@gmail.com.

Resumo: O desenvolvimento sustentável desafia a sociedade a fazer uso de práticas de desenvolvimento que garantam qualidade de vida para as gerações atuais e futuras. Nesse sentido, a agricultura sustentável visa uma produção agrícola com o mínimo de impactos ambientais possível. Diante disso, faz-se necessário inferir a sustentabilidade na agricultura com o uso de indicadores, que tem como objetivo monitorar os métodos de cultivo a fim de obter informações que determinem se os métodos utilizados são sustentáveis, permitindo também a identificação de aspectos que precisem ser melhorados. Dessa forma, a pesquisa realizada visou identificar o índice de sustentabilidade de produção agrícola das famílias assistidas pelo Projeto de Transposição do Rio São Francisco, em São José de Piranhas - PB. A pesquisa foi realizada nas Vilas Produtivas Rurais, localizadas no

\section{POLÊM!CA $\mid$ LABORE (}

Polêmica - Revista Eletrônica da Uerj - Rua São Francisco Xavier, 524, $1^{\circ}$ andar bloco D, sl.1001 • Tels.: +55 21 2334-4088 / 4087 • http://www.e-publicacoes.uerj.br/index.php/polemica/index http://www.labore.uerj.br • laboreuerj@yahoo.com.br 
município de São José de Piranhas, no período de 02 de outubro de 2017 a 30 de junho de 2018, e deu-se por meio de um questionário utilizado como instrumento de coleta de dados. Os resultados obtidos indicam que os agricultores assistidos pelo Projeto de Transposição do Rio São Francisco, em São José de Piranhas, não utilizam práticas agrícolas sustentáveis. $\mathrm{Na}$ análise dos dados foi observado que a agricultura familiar exercida nas Vilas Produtivas Rurais apresenta um baixo índice econômico $(0,10)$, um baixo índice técnico-agronômico $(0,49)$, um baixo índice de manejo $(0,03)$, um baixo índice ecológico $(0,06)$ e também um baixo índice político institucional $(0,13)$. De acordo com a metodologia utilizada na pesquisa, todos os indicadores apresentaram uma baixa sustentabilidade.

Palavras-chave: Desenvolvimento sustentável. Produção agrícola. Indicadores. Transposição.

\title{
SUSTAINABILITY OF THE AGRICULTURAL PRACTICES OF FAMILIES ASSISTED BY THE SÃO FRANCISCO RIVER TRANSPOSITION PROJECT IN SÃO JOSÉ DE PIRANHAS IN THE STATE OF PARAÍBA, BRAZIL
}

\begin{abstract}
Sustainable development challenges society to use practices that ensure the quality of life of both current and future generations. The goal of sustainable agriculture is to exert the least possible impact on the environment. The sustainability of agricultural practices can be inferred with the use of indicators designed to monitor farming methods to obtain data that determine whether the methods employed are sustainable as well as identify aspects that need to be improved. Therefore, the aim of the present study was to identify the sustainability index of farming production among families assisted by the São Francisco River transposition project in the municipality of São José de Piranhas in the state of Paraíba, Brazil. The study was conducted in productive rural communities of the municipality between October $2^{\text {nd }}, 2017$ and June 30 ${ }^{\text {th }}$, 2018. Data collection involved the administration of a questionnaire. The results indicate that farmers assisted by the transposition project do not use sustainable farming practices. The analysis of the data revealed that family farming practices in the rural communities have low economic (0.10), technical-agronomic (0.49), management (0.03), ecological (0.06) and institutional-political (0.13) indices. Based on the methods employed in the present study, all indicators point to low sustainability.
\end{abstract}

Keywords: Sustainable development. Agricultural production. Indicators. Transposition.

\section{Introdução}

"Desenvolvimento sustentável trata essencialmente das relações entre pessoas e entre pessoas e seu meio ambiente. Em outras palavras, é uma preocupação sociocultural e econômica" (UNESCO, 2005, p. 42). A sustentabilidade socioambiental propõe um tipo de desenvolvimento que garanta qualidade de vida para as gerações atuais e futuras. $\mathrm{O}$ estudo e reflexão sobre as implicações das ações antrópicas nos ecossistemas contribui para o aumento da sensibilização sobre os problemas ambientais gerados por padrões de vida incompatíveis com o processo de desenvolvimento sustentável (BELLEN, 2006).

Discutir ações voltadas à sustentabilidade socioambiental revela que as atuações nesse campo não devem ser orientadas de forma isolada, seja no acúmulo de riquezas, seja na proteção de recursos ambientais. Assim, faz-se necessário o aumento da capacidade política, social e ecológica de lidar com as mudanças, mantendo as opções para responder questões nas diferentes dimensões (PHILIPPI JR; MALHEIROS, 2013).

Nesse contexto, cabe pensar a agricultura, cujo exercício passou a receber críticas mais severas do ponto de vista sustentável, quando passou a adotar práticas de modernização,

\section{POLÊM!CA $\mid$ LABORE}

Polêmica - Revista Eletrônica da Uerj - Rua São Francisco Xavier, 524, $1^{\circ}$ andar bloco D, sl.1001 • Tels.: +55 21 2334-4088 / 4087 • http://www.e-publicacoes.uerj.br/index.php/polemica/index http://www.labore.uerj.br • laboreuerj@yahoo.com.br 
causando prejuízos significativamente impactantes. Os danos como a erosão do solo, contaminação causada por produtos químicos, causaram uma grande visibilidade política entre as décadas de 70 e 80 , abrindo caminho para o desenvolvimento de uma prática agrícola alternativa ao modelo hegemônico de produção agrícola (UZÊDA, 2004).

Portanto, a agricultura sustentável está em oposição a um modelo de agricultura que produz impactos ambientais e sociais negativos, indo contra qualquer tipo de degradação dos solos pela erosão, à desertificação, ao desflorestamento, à contaminação da água, do alimento e do agricultor, da redução da biodiversidade geral e funcional, da insegurança alimentar e aos impactos globais gerados pela agricultura de cunho convencional. Assim, a agricultura sustentável caracteriza-se por ser ecologicamente correta, economicamente viável, socialmente justa e adaptável. São propostas desafiadoras para produção de alimentos em harmonia com o homem e com o meio ambiente (UZÊEA, 2004).

Ao mensurar a sustentabilidade da produção agrícola, pode-se fazer uso de ferramentas que indiquem o nível de sustentabilidade dessa produção. Uma delas constitui-se nos indicadores de sustentabilidade, que têm como objetivo quantificar ou qualificar informações tornando-as mais significativas; eles simplificam informações, tentando melhorar o processo de comunicação e compreensão (BELLEN, 2006).

O uso de um conjunto de indicadores pode servir para avaliar o sistema e possibilitar seu monitoramento no decorrer do tempo, a fim de fornecer informações que determinem se o sistema de manejo utilizado é sustentável ou não, e também permitir a identificação dos aspectos que precisam ser melhorados. Silva (2016) considera os indicadores importantes, pois um de seus benefícios é avaliar a sustentabilidade de um determinado sistema de produção e simultaneamente aumentar a relação entre a agricultura familiar e o desenvolvimento sustentável.

Diante disso, a presente pesquisa teve por objetivo analisar a sustentabilidade de produção agrícola das famílias assistidas pelo Projeto de Transposição do Rio São Francisco no município de São José de Piranhas.

\section{POLÊM!CA $\mid$ LABORE}

Polêmica - Revista Eletrônica da Uerj - Rua São Francisco Xavier, 524, $1^{\circ}$ andar bloco D, sl.1001 • Tels.: +55 21 2334-4088/4087 • http://www.e-publicacoes.uerj.br/index.php/polemica/index http://www.labore.uerj.br • laboreuerj@yahoo.com.br 


\section{Procedimentos metodológicos}

Localização e descrição da área de estudo

O município de São José de Piranhas do Estado da Paraíba, está localizado na microrregião de Cajazeiras e está a uma distância de $503 \mathrm{~km}$ da capital João Pessoa. O município se estende por $677,3 \mathrm{~km}^{2}$ e conta com cerca de 20 mil habitantes, segundo estimativa do IBGE (2019), com densidade demográfica de 28,19 habitantes por km².

Figura - 1: Localização do município de São José de Piranhas no mapa da Paraíba.

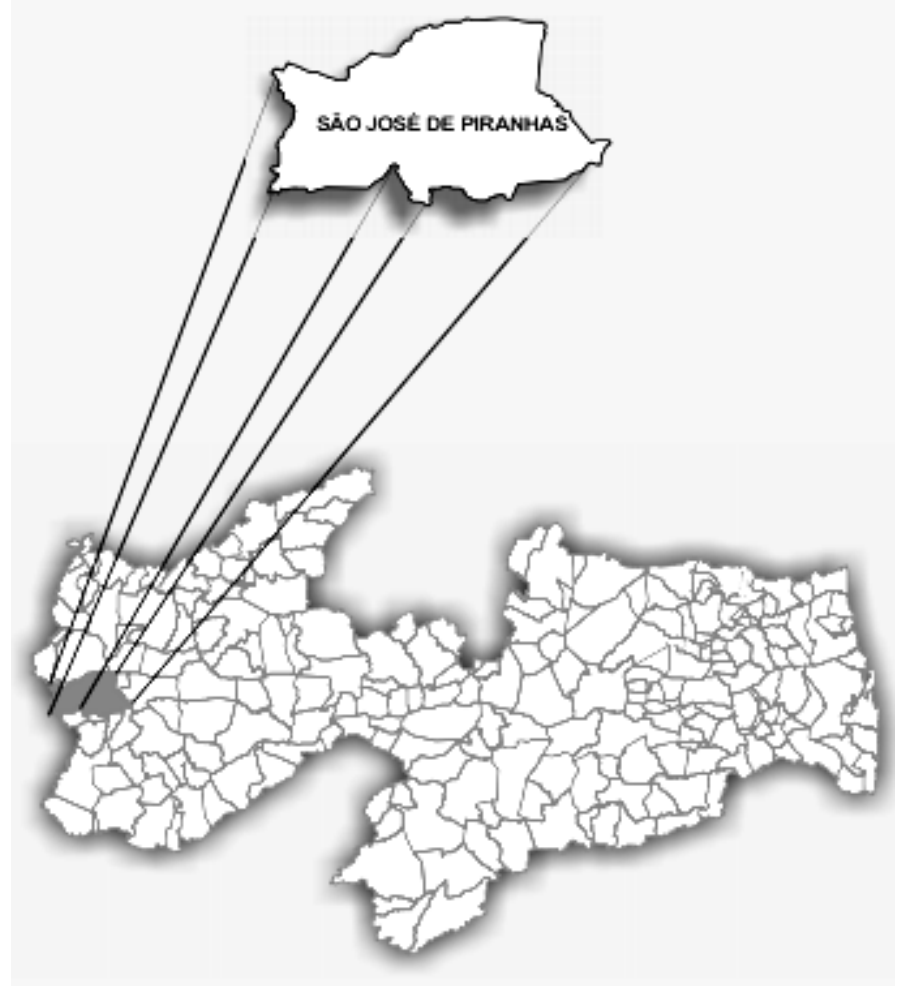

Fonte: CPRM (2005).

A pesquisa foi realizada nas Vilas Produtivas Rurais que fazem parte do Programa de Reassentamento de Populações, um dos programas socioambientais do Projeto de Transposição do Rio São Francisco. As comunidades onde a pesquisa foi desenvolvida foram as vilas produtivas Cacaré, Irapuá I e Irapuá II, ambas localizadas no município de São José de Piranhas - PB, fazendo parte do eixo norte e trecho III da Transposição do Rio São Francisco (FEITOSA et al., 2016).

\section{POLÊM!CA $\mid$ LABORE}

Polêmica - Revista Eletrônica da Uerj - Rua São Francisco Xavier, 524, $1^{\circ}$ andar bloco D, sl.1001 • Tels.: +55 21 2334-4088 / 4087 • http://www.e-publicacoes.uerj.br/index.php/polemica/index http://www.labore.uerj.br • laboreuerj@yahoo.com.br 


\section{Classificação da pesquisa}

Conforme Silva e Menezes (2005), do ponto de vista da sua natureza, a pesquisa é aplicada, pois ela objetiva gerar conhecimentos para aplicação prática e dirigidos à solução de problemas específicos, além de envolver verdades e interesses locais. Quanto a forma de abordagem do problema a pesquisa é quantitativa, pois traduz em números opiniões e informações a serem classificadas e analisadas. Em relação aos objetivos a pesquisa foi descritiva, pois, como diz o nome, visa descrever as características de determinada população fazendo uso de coleta de dados. Sob a perspectiva dos procedimentos técnicos, a pesquisa pode ser classificada como um levantamento, pois envolve a interrogação direta das pessoas cujo comportamento se deseja conhecer. Os pesquisadores e participantes estão envolvidos de modo cooperativo ou participativo.

\section{$\underline{\text { Sujeitos da pesquisa }}$}

Participaram da presente pesquisa agricultores residentes nas Vilas Produtivas Rurais Cacaré, Irapuá I e Irapuá II, respondendo à entrevista aqueles que estavam em suas residências no momento da visita dos pesquisadores e que concordaram em assinar o Termo de Consentimento Livre e Esclarecido. Por fim, a pesquisa contou com a participação de 45 famílias reassentadas.

\section{$\underline{\text { Instrumentos de coleta de dados }}$}

Como instrumento de coleta de informação foi utilizado um formulário estruturado, constando os indicadores da pesquisa a fim de obter dados suficientes para alcançar o objetivo proposto. A referida pesquisa foi aprovada pelo Comitê de Ética em Pesquisa (CEP), CAAE 84123317.8.0000.5575. Nas investigações, foi utilizada a transcrição manual dos depoimentos e gravação em áudio para transcrição posterior.

\section{Determinação do Índice de Sustentabilidade (IS)}

Para determinação do Índice de Sustentabilidade (IS), recorreu-se a metodologia de Oliveira (2007), por ser o primeiro trabalho relativo ao índice de sustentabilidade voltado para a produção agrícola. Para se determinar o índice da sustentabilidade dos agricultores familiares foi considerada a média ponderada dos efeitos de vários indicadores. A contribuição de cada

\section{POLÊM!CA $\mid$ LABORË}

Polêmica - Revista Eletrônica da Uerj - Rua São Francisco Xavier, 524, $1^{\circ}$ andar bloco D, sl.1001 • Tels.: +55 21 2334-4088 / 4087 • http://www.e-publicacoes.uerj.br/index.php/polemica/index http://www.labore.uerj.br • laboreuerj@yahoo.com.br 
variável "i" em determinada propriedade "j" na determinação do indicador "k" foi dada pela equação:

$$
\begin{aligned}
& \text { Equação - 1: } \\
& C_{i j k}=\frac{E_{i j k}}{E_{i k \text { max }}}
\end{aligned}
$$

Sendo:

Eijk - Escores das variáveis “ $i$ ” do indicador " $k$ " na propriedade “ $j ”$.

Eikmax - Valor máximo da $i$-ésima variável componente do indicador $k$.

A contribuição média da " $m$ " variáveis, em determinada propriedade " $j$ " na determinação do indicador " $k$ " foi determinada pela equação:

$$
\begin{aligned}
& \text { Equação - 2: } \\
& C_{j k}=\frac{1}{m} \sum_{i=1}^{m} C_{i j k}
\end{aligned}
$$

O valor do indicador " $k$ " foi obtido da seguinte forma:

$$
\begin{aligned}
& \text { Equação-3: } \\
& C_{k}=\frac{1}{n} \sum_{j=1}^{n} C_{j k}
\end{aligned}
$$

Sendo que:

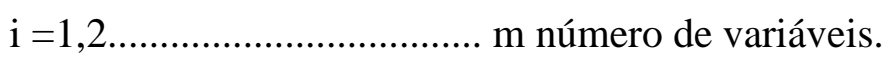

$\mathrm{j}=1,2 \ldots \ldots \ldots \ldots \ldots \ldots \ldots \ldots \ldots \ldots \ldots \ldots$ n número de produtores entrevistados.

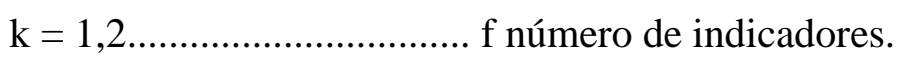

O Índice de Sustentabilidade (IS) foi então obtido através de:

Equação - 4:

$$
I S=\frac{1}{F} \sum_{k=1}^{F}\left(C_{k}\right)
$$

\section{POLÊM!CA | LABORE.}


A classificação do IS utilizando os indicadores econômico, técnico-agronômico, manejo, ecológico e político institucional também foi realizada de acordo com a metodologia de Oliveira (2007). O índice varia de zero (nenhuma sustentabilidade) a um (total sustentabilidade) e apresenta a seguinte classificação:

Baixa Sustentabilidade: $0,0<$ IS $\leq 0,5$

Média Sustentabilidade: $0,5<$ IS $\leq 0,8$

Alta Sustentabilidade: $0,8<$ IS $\leq 1,0$

\section{$\underline{\text { Análise dos dados }}$}

Para obtenção do IS utilizou-se uma planilha eletrônica para calcular, inicialmente, a média de cada indicador das propriedades individualmente. Em seguida foi feita a média de cada indicador de todas as propriedades e, por fim, a média do Índice de Sustentabilidade Geral de todos os indicadores. Para discussão dos resultados foram utilizados resultados de pesquisas anteriores de investigações relacionadas a temática do presente estudo. A busca por tal material se deu em duas categorias: pesquisa por literatura cinzenta e seleção de artigos. Os trabalhos selecionados foram avaliados na íntegra.

\section{Resultados e discussões}

Após análise dos dados, verificou-se que 17,8\% dos agricultores pesquisados têm entre 18 e 29 anos, 22,2\% têm entre 30 e 39 anos, 24,4\% têm entre 40 e 49 anos, 17,8\% têm entre 50 e 59 anos, 6,7 \% têm entre 60 e 69 anos e 11,1\% têm entre 70 e 88 anos. Diante disso, percebemos que, na região pesquisada, a maioria dos agricultores tem mais de 30 anos. Podese observar resultados semelhantes à pesquisa realizada no Semiárido paraibano por Barros, Chaves e Farias (2014) na qual constataram que os agricultores entrevistados apresentavam uma idade superior a 25 anos de idade. Nesse ponto percebeu-se que poucos jovens trabalham com agricultura na região; talvez exista um desinteresse da parte dos mesmos, pois, de acordo com Zago (2016), o êxodo rural nas regiões de predomínio da agricultura familiar, atualmente, tem atingido as populações jovens com intensidade.

Do ponto de vista da escolaridade, 26,6\% dos agricultores pesquisados são analfabetos, $46,7 \%$ possuem o ensino fundamental incompleto, 6,7\% possuem o ensino fundamental completo, $8,9 \%$ tem o ensino médio incompleto e $11,1 \%$ tem o ensino médio completo. Pode-

\section{POLÊM!CA $\mid$ LABORẸ}

Polêmica - Revista Eletrônica da Uerj - Rua São Francisco Xavier, 524, $1^{\circ}$ andar bloco D, sl.1001 • Tels.: +55 21 2334-4088/4087 • http://www.e-publicacoes.uerj.br/index.php/polemica/index http://www.labore.uerj.br • laboreuerj@yahoo.com.br 
se destacar um número considerável de analfabetos entre os entrevistados e uma escolaridade - quando há - reduzida aos primeiros anos do ensino fundamental. Diante disso, é possível considerar que o grau de escolaridade dos produtores agrícolas assistidos pelo Projeto de Transposição do Rio São Francisco em São José de Piranhas é baixo. A pesquisa de Rebouças e Lima (2013) também resultou em uma baixa escolaridade dos pesquisados, onde 10\% são analfabetos e, entre os demais, a maioria possui apenas o nível fundamental. Significativa também foi a pesquisa de Barros, Chaves e Farias (2014), realizada no Sertão paraibano, na qual verificaram que $47,1 \%$ dos entrevistados eram analfabetos.

Apontado o perfil dos entrevistados, adentra-se na discussão dos indicadores que, voltados à avaliação da sustentabilidade da produção agrícola, são ferramentas que podem contribuir para redimensionar as práticas agrícolas desenvolvidas em determinada localidade. Assim, no presente estudo é realizada a avaliação do IS, recorrendo ao agrupamento de vários indicadores nos fatores econômicos, técnico-agronômico, manejo, ecológico e político institucional.

\section{Indicador Econômico}

O indicador econômico contribui para avaliação da sustentabilidade de uma região ao permitir que o pesquisador tenha conhecimento sobre a condição econômica dos agricultores e como seus recursos são aplicados em sua prática agrícola. Além disso, possibilita a análise do processo de administração dos bens produzidos. Porém, para a análise de sustentabilidade aqui obtida serve como recurso parcial, pois o índice de sustentabilidade de um indicador está sujeito aos demais indicadores (DEPONTI, 2002).

Quadro - 1: Indicadores variável econômica

\begin{tabular}{|l|c|c|c|c|}
\hline \multirow{2}{*}{ INDICADORES } & \multicolumn{2}{|c|}{ Sim } & \multicolumn{2}{c|}{ Não } \\
\cline { 2 - 5 } & $\mathbf{N}$ & $\mathbf{F i}$ & $\mathbf{N}$ & $\mathbf{F i}$ \\
\hline Principal atividade econômica familiar é agrícola? & 32 & 71,1 & 13 & 28,9 \\
\hline Atividade agrícola é feita na própria propriedade? & 41 & 91,1 & 4 & 8,9 \\
\hline Propriedade onde mora é própria? & 44 & 97,8 & 1 & 2,2 \\
\hline $\begin{array}{l}\text { O tamanho da propriedade é suficiente para a produção } \\
\text { agrícola da família? }\end{array}$ & 32 & 71,1 & 13 & 28,9 \\
\hline $\begin{array}{l}\text { Renda familiar é resultante apenas da agricultura } \\
\text { familiar? }\end{array}$ & 12 & 26,9 & 33 & 73,3 \\
\hline Há um controle dos custos de suas atividades? & 8 & 17,8 & 37 & 82,2 \\
\hline É agricultor permanente? & 43 & 95,6 & 2 & 4,4 \\
\hline
\end{tabular}

Legenda: $\mathrm{N}=$ Frequência absoluta; $\mathrm{Fi}$ = Frequência relativa.

\section{POLÊM!CA | LABORE}

Polêmica - Revista Eletrônica da Uerj - Rua São Francisco Xavier, 524, $1^{\circ}$ andar bloco D, sl.1001 • Tels.: +55 21 2334-4088/4087 • http://www.e-publicacoes.uerj.br/index.php/polemica/index http://www.labore.uerj.br • laboreuerj@yahoo.com.br 
Fonte: Os autores, 2018.

A partir das entrevistas verificou-se que a maioria dos produtores são agricultores permanentes, sendo a agricultura a principal atividade econômica da família, e para $91,1 \%$ dos casos, a mesma é realizada na própria propriedade (Figura 2), como afirma Cavalcanti et al. (2000). No semiárido nordestino, a maioria dos pequenos agricultores dependem da renda obtida da produção agrícola e pecuária. Na grande maioria dos casos, a propriedade rural pertence ao produtor, o que lhe permite autonomia no trabalho e maior lucro na produção, diferentemente da pesquisa de Aguiar e Monteiro (2005), onde 85\% dos produtores não eram os donos da propriedade.

Segundo $71,1 \%$ dos agricultores, a propriedade tem tamanho suficiente para produção familiar. A extensão da propriedade é um fator relevante para a produção agropecuária no Semiárido, porém, não deve ser considerado o único ou fator determinante. No documento Agricultura de Precisão (BRASIL, 2013) é apontado que o tamanho da propriedade utilizada pelo produtor é o menos importante, pois o sucesso da produção depende da capacidade do produtor de controlar os custos de sua produção.

Figura - 2: Atividade agrícola desenvolvida na própria propriedade do produtor (Irapuá II)

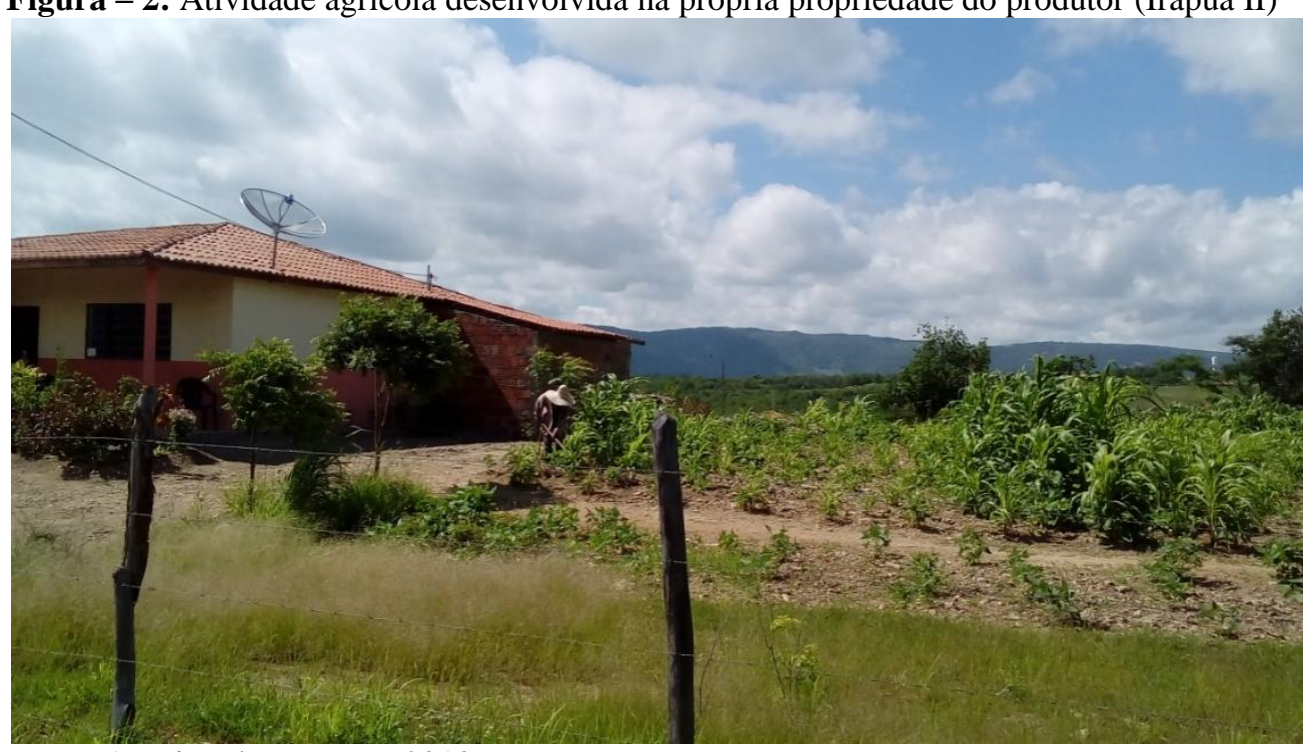

Fonte: Arquivo dos autores, 2018.

Geralmente, no Semiárido, o produtor agrícola tem uma renda estacional, dependendo do período de produção e colheita, ou seja, obtém a renda familiar da produção agropecuária que está relacionada diretamente ao período chuvoso. Sendo assim, é de significativa relevância

\section{POLÊM!CA $\mid$ LABORE}

Polêmica - Revista Eletrônica da Uerj - Rua São Francisco Xavier, 524, $1^{\circ}$ andar bloco D, sl.1001 • Tels.: +55 21 2334-4088 / 4087 • http://www.e-publicacoes.uerj.br/index.php/polemica/index http://www.labore.uerj.br • laboreuerj@yahoo.com.br 
a gestão incorporada ao processo. A pesquisa mostrou que 17,8\% dos entrevistados realizam o controle de custos de sua produção; um percentual baixo. Nesse contexto, Oliveira et al. (2016) afirmam que o trabalho dos pequenos produtores se tornou mais difícil diante das limitações dos mesmos em acompanhar as tecnologias agrícolas, nesse caso, o controle de custos juntamente com a análise da produtividade é prejudicado. O resultado é expressivo quando se vê que, majoritariamente, essa atividade é a principal da família.

Diante disso, para 73,3\% dos pesquisados, a agricultura não é a única fonte de renda da família, e os mesmos utilizam de assistências governamentais como aposentadoria, auxílio moradia e Bolsa Família. Bezerra e Schlindwein (2017) concluíram em seu estudo que muitos produtores agrícolas, além de consumirem e comercializarem seus produtos, procuram meios que lhes possibilitem uma renda extra.

Perante o exposto, observou-se um índice econômico de 0,10, apontando uma baixa sustentabilidade. Isso indica que a prática da agricultura familiar não está contribuindo para o desenvolvimento econômico das famílias assistidas pelo projeto de Transposição do Rio São Francisco. Esse dado se assemelha ao relatado por Santos (2010), que observou em Lagoa Seca - PB o índice econômico de 0,4479, indicando também uma baixa sustentabilidade.

Nessa perspectiva, é preciso repensar o processo, em seus pontos positivos e negativos, para que o produtor agrícola encontre meios de melhorar sua condição de vida, assegurando renda e sustentabilidade ambiental para sua família, utilizando tudo que a terra pode lhe oferecer sem causar danos ao meio ambiente.

\section{Indicador Técnico-Agronômico}

O indicador técnico-agronômico aborda o tempo de trabalho na agricultura e o uso de práticas agroecológicas (tais como adubação orgânica, rotação de culturas, uso racional dos recursos hídricos, entre outras ações) por parte dos produtores rurais, que leva em consideração uma melhor produtividade, preservando o solo e a biodiversidade.

Quadro - 2: Indicadores variável Técnico-agronômico

\begin{tabular}{|l|c|c|c|c|}
\hline \multirow{2}{*}{ INDICADORES } & \multicolumn{2}{|c|}{ Sim } & \multicolumn{3}{|c|}{ Não } \\
\cline { 2 - 5 } & $\mathbf{N}$ & $\mathbf{F i}$ & $\mathbf{N}$ & Fi \\
\hline Trabalha há mais de cinco anos com agricultura? & 44 & 97,8 & 1 & 2,2 \\
\hline Fez adoção de práticas agroecológicas? & 6 & 13,3 & 39 & 86,7 \\
\hline
\end{tabular}

Legenda: N = Frequência absoluta; Fi = Frequência relativa.

Fonte: Os autores, 2018.

\section{POLÊM!CA $\mid$ LABORE}

Polêmica - Revista Eletrônica da Uerj - Rua São Francisco Xavier, 524, $1^{\circ}$ andar bloco D, sl.1001 • Tels.: +55 21 2334-4088/4087 • http://www.e-publicacoes.uerj.br/index.php/polemica/index http://www.labore.uerj.br • laboreuerj@yahoo.com.br 
Nesse quesito, percebe-se que quase todos os produtores entrevistados $(97,8 \%)$ trabalham na agricultura há mais de cinco anos, o que é comum, pois a agricultura é uma prática cultural transmitida de geração em geração. Muitos agricultores cresceram vendo seus pais nessa prática e adquiriram a mesma como profissão. Diferentemente há a pesquisa realizada no Sertão paraibano por Barros e Pordeus (2016b), na qual identificou-se que os produtores trabalhavam na agricultura há 2 e 3 anos. Uma característica que diferencia a pesquisa realizada pelos autores anteriormente citados e o presente estudo é o fato de que a pesquisa destes foi desenvolvida junto a agricultores que possuem acesso à água para os meios de produção agrícola, ou seja, são proprietários de lotes localizados em um perímetro irrigado.

No que diz respeito ao uso de práticas agroecológicas, notou-se que apenas 13,3\% dos agricultores adotam práticas agrícolas sustentáveis, o que aumenta o impacto ambiental negativo nos ecossistemas locais - resultado discordante do encontrado por Barros e Pordeus (2016b). De acordo com Barros e Pordeus (2016a), as práticas agroecológicas são relevantes na agricultura familiar no Semiárido, tendo em vista que nessa região predomina a escassez de água, solos deteriorados e deficiência de políticas públicas. Neste aspecto, sua adoção contribui com o desenvolvimento de ações voltadas para a convivência com esse ambiente que apresenta características próprias.

Sendo assim, o índice técnico-agronômico apresentou uma baixa sustentabilidade de 0,49. Mesmo assim, se mostrou a variável que menos colaborou para o resultado final do IS da agricultura na região - que será visto posteriormente. Comparando com Oliveira (2007), podese observar a grande diferença dos resultados, tendo em vista que na Associação dos Produtores orgânicos de Ibiapaba - CE, seu lócus de pesquisa, o resultado foi 1, indicando uma alta sustentabilidade.

\section{Indicador de Manejo}

O índice de manejo expressa os tipos de práticas agrícolas adotadas pelos produtores (conforme Quadro 3) e também se as mesmas garantem a conservação do solo. Mensurar as práticas de manejo na agricultura é uma estratégia relevante, tendo em vista que a manutenção e conservação do solo são preponderantes para que haja uma produção agrícola sustentável em longo prazo.

\section{POLÊM!CA $\mid$ LABORE}

Polêmica - Revista Eletrônica da Uerj - Rua São Francisco Xavier, 524, $1^{\circ}$ andar bloco D, sl.1001 • Tels.: +55 21 2334-4088/4087 • http://www.e-publicacoes.uerj.br/index.php/polemica/index http://www.labore.uerj.br • laboreuerj@yahoo.com.br 
Quadro - 3: Indicadores variável Manejo

\begin{tabular}{|l|c|c|c|c|}
\hline \multirow{2}{*}{ INDICADORES } & \multicolumn{2}{|c|}{ Sim } & \multicolumn{2}{c|}{ Não } \\
\cline { 2 - 5 } & $\mathbf{N}$ & $\mathbf{F i}$ & $\mathbf{N}$ & $\mathbf{F i}$ \\
\hline Há treinamento para trabalhar com agricultura sustentável? & 14 & 31,1 & 31 & 68,9 \\
\hline Utiliza mecanização de tração animal? & 0 & 0 & 45 & 100 \\
\hline Faz rotação de cultura? & 0 & 0 & 45 & 100 \\
\hline Utiliza consórcio? & 24 & 53,3 & 21 & 46,7 \\
\hline Faz adubação verde? & 1 & 2,2 & 44 & 97,8 \\
\hline Faz adubação orgânica (esterco)? & 3 & 6,7 & 42 & 93,3 \\
\hline Utiliza semente selecionada? & 16 & 35,6 & 29 & 64,4 \\
\hline Faz uso de estufas? & 0 & 0 & 45 & 100 \\
\hline Faz irrigação? & 0 & 0 & 45 & 100 \\
\hline
\end{tabular}

Legenda: $\mathrm{N}=$ Frequência absoluta; Fi = Frequência relativa.

Fonte: Os autores, 2018.

Segundo Kamiyama (2011), a atividade agrícola sustentável beneficia o agricultor familiar, pois faz uso dos recursos naturais de forma racional, prolongando sua capacidade de produção. No entanto, apenas $31,1 \%$ dos produtores tiveram acesso a treinamentos para trabalhar com agricultura sustentável, o que contribuiu muito para o baixo índice de sustentabilidade na questão do manejo. $\mathrm{O}$ índice resultou em 0,03 - o que também difere de Santos (2010), em que os resultados indicam uma média sustentabilidade, de 0,7221.

No que se refere ao uso de tração animal, esta técnica é uma alternativa econômica para uma pequena propriedade, servindo de montaria, transporte de mercadorias e podendo ser utilizado em qualquer terreno (VIEIRA, 2014). Porém, nenhum dos produtores utiliza essa prática para preparação do solo, fazem todo o serviço de cultivo manualmente.

No tocante à utilização de plantio consorciado, prática que promove a diversidade biológica e melhor controle de pragas, 53,3\% dos agricultores o adotam, plantando geralmente milho e feijão (Figura 3). De acordo com Filho et al. (2016), ambos estão entre as culturas mais utilizadas no Brasil.

\section{POLÊM!CA | LABORE}

Polêmica - Revista Eletrônica da Uerj - Rua São Francisco Xavier, 524, $1^{\circ}$ andar bloco D, sl.1001 • Tels.: +55 21 2334-4088 / 4087 • http://www.e-publicacoes.uerj.br/index.php/polemica/index http://www.labore.uerj.br • laboreuerj@yahoo.com.br 


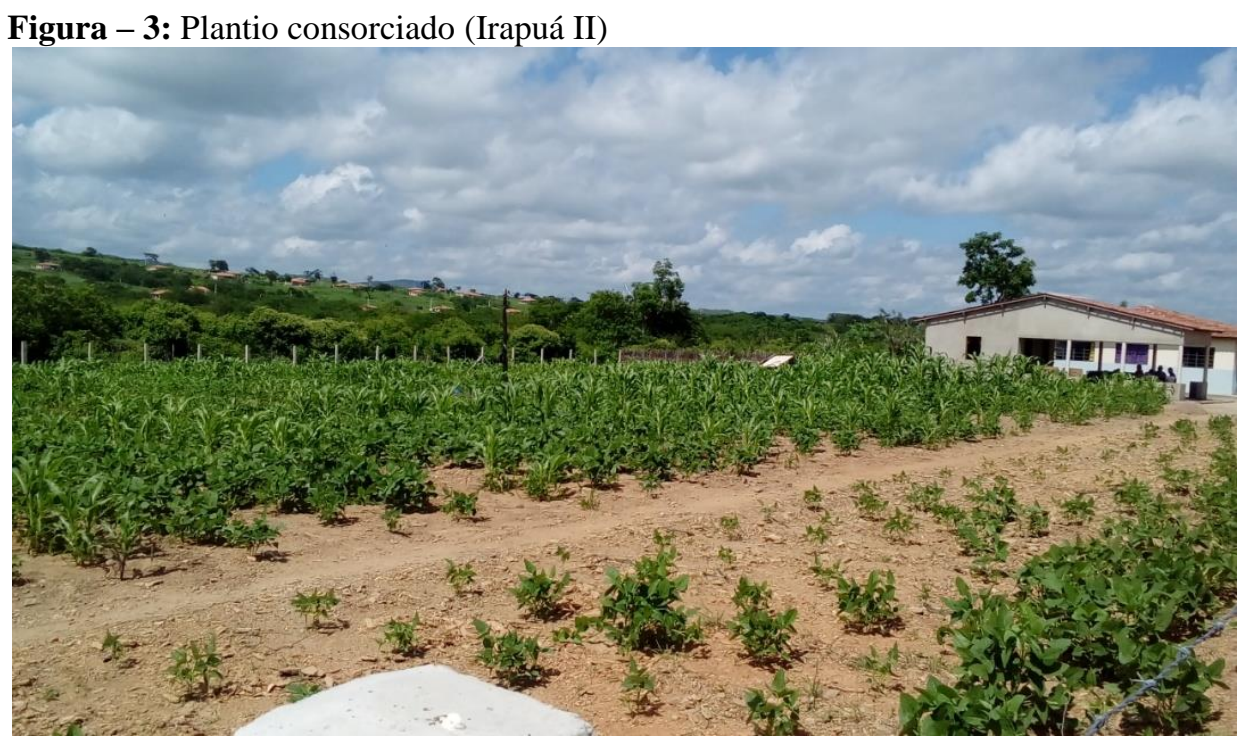

Fonte: Arquivo dos autores, 2018.

A pesquisa revelou também que pouquíssimos produtores rurais da área de estudo $(13,3 \%)$ utilizam algum tipo de adubação verde ou orgânica que, conforme Finato et al. (2013), melhora a produtividade e a fertilidade do solo, aumentando assim a diversidade biológica do mesmo. Assim, o uso dessa prática poderia promover uma melhor qualidade da agricultura local.

Além disso, apenas 35,6\% dos agricultores utilizam semente selecionada de colheitas anteriores, ou seja, sementes criolas, um fator negativo tendo em vista que as sementes criolas asseguram fonte genética e mais condições a adaptações. Segundo Paterniani (2001), a forma mais tradicional de agricultura sustentável não faz uso de sementes selecionas artificialmente ou geneticamente melhoradas.

Foi observado também que os produtores não fazem uso de estufas, fato este relacionado às condições econômicas dos reassentados e às características da produção agrícola tradicional no Semiárido brasileiro. Resultados discordantes foram encontrados por Vargas (2012), onde o autor verificou que em 28,7\% dos casos são utilizadas estufas. Pode-se de igual modo ver que a irrigação também é uma prática que não é adotada pelos produtores pesquisados, conforme o Atlas da Irrigação (BRASIL, 2017); o Semiárido brasileiro é uma região que sofre com a pouca disponibilidade de água, sendo, no entanto, a irrigação relevante para viabilidade da agricultura.

\section{POLÊM!CA $\mid$ LABORE}

Polêmica - Revista Eletrônica da Uerj - Rua São Francisco Xavier, 524, $1^{\circ}$ andar bloco D, sl.1001 • Tels.: +55 21 2334-4088 / 4087 • http://www.e-publicacoes.uerj.br/index.php/polemica/index http://www.labore.uerj.br • laboreuerj@yahoo.com.br 
Indicador Ecológico

O indicador ecológico busca analisar se os agricultores utilizam práticas agrícolas que visam minimizar os danos causados ao solo e ao meio ambiente, tais como conservação do solo, controle natural de pragas, entre outros.

Quadro - 4: Indicadores variável Ecológico

\begin{tabular}{|l|c|c|c|c|}
\hline \multirow{2}{*}{ INDICADORES } & \multicolumn{2}{|c|}{ Sim } & \multicolumn{2}{c|}{ Não } \\
\cline { 2 - 5 } & $\mathbf{N}$ & $\mathbf{F i}$ & $\mathbf{N}$ & $\mathbf{F i}$ \\
\hline Na sua propriedade há área de preservação? & 20 & 44,4 & 25 & 55,6 \\
\hline Faz uso de agrotóxico? & 26 & 57,8 & 19 & 42,2 \\
\hline Usa fertilizantes químicos? & 1 & 2,2 & 44 & 97,8 \\
\hline Faz controle natural de pragas e doenças? & 3 & 6,7 & 42 & 93,3 \\
\hline Sempre planta a mesma cultura? & 43 & 95,6 & 2 & 4,4 \\
\hline Utiliza práticas de conservação do solo? & 7 & 15,6 & 38 & 84,4 \\
\hline Faz a reciclagem dos resíduos? & 7 & 15,6 & 38 & 84,4 \\
\hline
\end{tabular}

Legenda: $\mathrm{N}$ = Frequência absoluta; $\mathrm{Fi}$ = Frequência relativa.

Fonte: Os autores, 2018.

Nesse ponto da pesquisa, pode-se observar que quase metade das propriedades pesquisadas possui área de preservação, áreas que têm sua fauna e flora protegidas pela legislação brasileira. Para Klein e Rosa (2011), as áreas de preservação ambiental são de grande importância para toda sociedade, por isso, o agricultor precisa respeitar os seus limites.

De acordo com o Código Florestal brasileiro (BRASIL, 2012), a lei estabelece regras sobre a proteção da vegetação, áreas de Preservação Permanente e as áreas de Reserva Legal, limitando a exploração florestal, o suprimento de matéria-prima, entre outros, delimitando a área de preservação ambiental - sendo 100 (cem) metros em zonas rurais, exceto para o corpo d'água com até 20 (vinte) hectares de superfície, cuja faixa marginal será de 50 (cinquenta) metros.

No que se refere a produtos químicos aplicados na plantação, a maioria dos produtores faz uso de agrotóxicos, prejudicando o solo diminuindo sua fertilidade, diferentemente do resultado da pesquisa realizada no Semiárido nordestino por Silva, Silva e Pereira (2015) onde foi constatada que as famílias pesquisadas não fazem uso de agrotóxicos.

Quanto às práticas de conservação do solo (a exemplo da rotação de culturas, adubação verde e orgânica), apenas 15,6\% dos produtores pesquisados afirmaram empregá-las, resultado que contrasta com a pesquisa de Barros, Chaves e Farias (2014), onde 83,8\% dos entrevistados empregavam essas práticas.

\section{POLÊM!CA $\mid$ LABORE}

Polêmica - Revista Eletrônica da Uerj - Rua São Francisco Xavier, 524, $1^{\circ}$ andar bloco D, sl.1001 • Tels.: +55 21 2334-4088 / 4087 • http://www.e-publicacoes.uerj.br/index.php/polemica/index http://www.labore.uerj.br • laboreuerj@yahoo.com.br 
Quase todos os produtores plantam sempre a mesma cultura, o que constitui um modelo inadequado, tendo em vista a ausência de diversificação da produção agrícola. Foi verificado também que os agricultores entrevistados não adotam a reciclagem de resíduos, prática que poderia melhorar a qualidade do solo e diminuir o descarte inadequado de resíduos produzidos na propriedade. Pode-se assim notar a diferença com a pesquisa realizada por Nogueira, Silva e Garcia (2013), em que é constatada a reutilização de resíduos sólidos na compostagem e também no artesanato, gerando assim uma renda extra para os assentados.

Além disso, a grande maioria dos produtores não faz uso de fertilizantes, o que pode amenizar os danos causados ao solo - diferentemente do estudo de Oliveira et al. (2015), em que foi constatado que os agricultores pesquisados utilizam fertilizantes químicos durante a adubação. Os produtores também não fazem controle natural de pragas e doenças. De acordo com Colmenarez et al. (2017), esse controle é de difícil implementação, devido à falta de conhecimento dos agricultores e também à falta de políticas públicas que os auxiliem na implementação e manejo dessa prática.

Assim, o índice ecológico também resultou em uma baixa sustentabilidade, tendo um valor de 0,06, em contraste com a pesquisa de Oliveira (2007), na qual foi constato um índice 1. Os dados da presente pesquisa apontam para adoção de práticas agrícolas não conservacionistas, fazendo-se necessário a adoção de modelos sustentáveis de produção agropecuária que, segundo Prado, Turetta e Andrade (2010), contribuem para a biodiversidade e fertilidade do solo.

\section{Indicador Político Institucional}

$\mathrm{O}$ indicador político institucional refere-se ao envolvimento dos produtores com o governo e instituições governamentais no tocante a receber algum tipo de apoio e/ou financiamento, sendo ações indispensáveis para que o pequeno produtor rural tenha acessos a novos nichos de mercado e produção agropecuária.

Quadro - 5: Indicadores variável Político Institucional.

\begin{tabular}{|l|c|c|c|c|}
\hline \multirow{2}{*}{ INDICADORES } & \multicolumn{2}{|c|}{ SIM } & \multicolumn{3}{|c|}{ Ñ̃O } \\
\cline { 2 - 6 } & $\mathbf{N}$ & $\mathbf{F i}$ & $\mathbf{N}$ & $\mathbf{F i}$ \\
\hline Há assistência técnica ou financeira do governo Federal? & 41 & 88,9 & 5 & 11,1 \\
\hline Há assistência técnica ou financeira do governo Estadual? & 1 & 2,2 & 44 & 97,8 \\
\hline $\begin{array}{l}\text { Há assistência técnica ou financeira do governo } \\
\text { Municipal? }\end{array}$ & 1 & 2,2 & 44 & 97,8 \\
\hline
\end{tabular}

\section{POLÊM!CA $\mid$ LABORE}

Polêmica - Revista Eletrônica da Uerj - Rua São Francisco Xavier, 524, $1^{\circ}$ andar bloco D, sl.1001 • Tels.: +55 21 2334-4088/4087 • http://www.e-publicacoes.uerj.br/index.php/polemica/index http://www.labore.uerj.br • laboreuerj@yahoo.com.br 


\begin{tabular}{|c|c|c|c|c|}
\hline Recebe assistência da EMPAER ${ }^{*}$ ? & 6 & 13,3 & 39 & 86,7 \\
\hline Há associação de agricultores? & 43 & 95,6 & 2 & 4,4 \\
\hline Há a socialização dos produtores vinculados associados? & 41 & 91,1 & 4 & 8,9 \\
\hline Há assistência por parte do sindicato do município? & 37 & 82,2 & 8 & 17,8 \\
\hline
\end{tabular}

Legenda: $\mathrm{N}=$ Frequência absoluta; $\mathrm{Fi}=$ Frequência relativa.

Fonte: Os autores, 2018.

*Empresa Paraibana de Pesquisa, Extensão Rural e Regularização Fundiária (EMPAER).

Observa-se que $88,9 \%$ dos agricultores afirmam receber assistência técnica ou financeira do Governo Federal; diferentemente dos Governos Estadual e Municipal, onde apenas 2,2\% afirmaram receber assistência técnica ou financeira. Além disso, 82,2\% afirmam receber assistência do sindicato do município, que se dá em forma de apoio às suas reivindicações e cumprimento de seus direitos. Pode-se observar exatamente o contrário na pesquisa de Barros, Chaves e Farias (2014), onde foi verificado que 91,2\% dos entrevistados não recebem nenhum tipo de assistência.

De acordo com Sassi (2005), atualmente a assistência técnica é de grande importância para qualquer atividade comercial, destacando a necessidade de implementação de políticas públicas voltadas a assistência técnica e financeira para o agricultor familiar. No entanto, muitos agricultores não são contemplados.

Com relação à EMPAER, apenas 13,3\% dos agricultores afirmaram receber assistência, e apenas quando solicitado. Uma grande crítica feita pelos pesquisados é que a EMPAER raramente colabora com o produtor, pois de acordo com Castro (2015), a assistência que oferta, bem como seu funcionamento dependem dos governos estaduais.

A maioria dos agricultores, um total de 95,6\%, afirmaram que há associação de agricultores em suas comunidades, sendo que 8,7\% não são vinculados e 91,1\% afirmaram socializar e interagir com os demais produtores. Caso semelhante foi encontrado na pesquisa de Barros, Chaves e Farias (2014), onde foi constatado que 92,6\% dos entrevistados participam da associação local de agricultores e 7,4\% não são vinculados.

As associações de agricultores exploram o trabalho coletivo com o foco de tornar as atividades economicamente mais rentáveis e sustentáveis (TONICASSO et al., 2007). Muitos produtores que participaram da pesquisa afirmam que participaram de treinamentos voltados para a prática agrícola oferecidos pelo sindicato do município, sendo instruídos de como utilizar os instrumentos e equipamentos de segurança de maneira adequada.

\section{POLÊM!CA $\mid$ LABORE}

Polêmica - Revista Eletrônica da Uerj - Rua São Francisco Xavier, 524, $1^{\circ}$ andar bloco D, sl.1001 • Tels.: +55 21 2334-4088 / 4087 • http://www.e-publicacoes.uerj.br/index.php/polemica/index http://www.labore.uerj.br • laboreuerj@yahoo.com.br 
Por fim, o indicador político institucional resultou em um índice de baixa sustentabilidade de 0,13. Pode-se entender que esse resultado negativo está relacionado diretamente à ausência ou insuficiência de políticas públicas voltadas para a produção agrícola familiar na região.

\section{$\underline{\text { Índice de sustentabilidade }}$}

Após coleta e análise dos dados e também do cálculo de cada indicador de sustentabilidade, é possível observar cada ponto da pesquisa e como eles contribuem para o índice de sustentabilidade de produção agrícola das famílias assistidas pelo Projeto de Transposição do Rio São Francisco em São José de Piranhas - PB. Na tabela abaixo pode-se observar os indicadores de sustentabilidade e seus respectivos índices, apontando para o Índice de Sustentabilidade das referidas famílias.

Quadro - 6: Índice de Sustentabilidade Geral.

\begin{tabular}{|l|l|}
\hline \multicolumn{2}{|l|}{ ÍNDICE DE SUSTENTABILIDADE GERAL } \\
\hline INDICADORES & IS DAS FAMÍLIAS \\
\hline Econômico & 0,10 \\
\hline Técnico-Agronômico & 0,49 \\
\hline Manejo & 0,03 \\
\hline Ecológico & 0,06 \\
\hline Político Institucional & 0,13 \\
\hline IS Geral & 0,20 \\
\hline Fon
\end{tabular}

Fonte: Os autores, 2018.

As informações expostas no quadro mostram que todos os indicadores contribuíram negativamente para o índice de sustentabilidade na região pesquisada e os indicadores que mais colaboraram com esse resultado foram o de Manejo $(0,03)$ e o Ecológico $(0,06)$, tendo em vista pontos negativos como o fato de que a grande maioria dos agricultores não teve treinamento para trabalhar com agricultura sustentável. Planta-se sempre a mesma cultura e não adota-se práticas de conservação do solo, o que promove seu desgaste e sua pouca fertilidade.

Diante disso, pode-se constatar que os agricultores assistidos pelo Projeto de Transposição do Rio São Francisco, em São José de Piranhas, não utilizam práticas agrícolas sustentáveis, uma vez que todos os indicadores apresentaram baixa sustentabilidade, resultando em um baixo Índice de Sustentabilidade de 0,20, estando no intervalo de $0,0<\mathrm{IS} \leq 0,5$

\section{POLÊM!CA | LABORE}

Polêmica - Revista Eletrônica da Uerj - Rua São Francisco Xavier, 524, $1^{\circ}$ andar bloco D, sl.1001 • Tels.: +55 21 2334-4088 / 4087 • http://www.e-publicacoes.uerj.br/index.php/polemica/index http://www.labore.uerj.br • laboreuerj@yahoo.com.br 


\section{Conclusões}

A maioria dos agricultores pesquisados tem mais de 30 anos e grau de escolaridade baixo, tendo em vista que a maioria deles não concluiu o ensino fundamental. Possivelmente o baixo nível de escolaridade dos produtores justifica a baixa sustentabilidade da produção agrícola nas Vilas Produtivas Rurais pesquisadas.

O cálculo do Índice de sustentabilidade resultou em 0,20, indicando uma baixa sustentabilidade, o que mostra que a agricultura familiar exercida nas Vilas Produtivas pesquisadas não é sustentável. Nesse sentido, constatou-se que os indicadores de manejo e o ecológico foram os que mais contribuíram para esse baixo resultado, considerando que os produtores não adotam práticas de conservação do solo.

Diante disso, podemos dizer que a produção agrícola das famílias assistidas pelo Projeto de Transposição do Rio São Francisco em São José de Piranhas precisa evoluir, adotando práticas agrícolas que promovam a conservação dos recursos naturais, proporcionando assim o aumento do nível de sustentabilidade.

Assim, faz-se necessário que os produtores adotem práticas agrícolas menos agressivas ao meio ambiente. Para isso, os agricultores precisam ter acesso e formação com vistas a adoção das tendências alternativas de produção agrícola sustentável, com o propósito de efetivar o desenvolvimento de tecnologias local e regionalmente adequadas, na ótica econômica, social e ambiental, tendo em vista a sustentabilidade da produção agrícola local.

\section{Referências}

AGUIAR, T. J. A.; MONTEIRO, M. S. L. Modelo agrícola e desenvolvimento sustentável: A ocupação do cerrado piauiense. Ambiente \& Sociedade, São Paulo, v. 8, n. 2, p. 161-178, jul./dez. 2005.

BARROS, J. D. de S.; CHAVES, L. H. G.; FARIAS, S. A. R. Aspectos socioeconômicos na microbacia hidrográfica do Riacho Val Paraíso - PB. Revista Brasileira de Gestão e Desenvolvimento Regional, Santa Cruz do Sul, v. 19, n. 1, p. 169-187, jan./abr. 2014.

BARROS, J. D. de S.; PORDEUS, A. V. Agricultura no Semiárido Brasileiro: Desafios e Potencialidades na Adoção de Práticas Agrícolas Sustentáveis. In: Congresso Internacional da Diversidade do Semiárido, 1, 2016, Campina Grande. Anais... Campina Grande: Editora Realize, 2016a.

BARROS, J. D. de S.; PORDEUS, A. V. Agricultura orgânica: caracterização das Produtoras no perímetro irrigado várzeas de Sousa. In: Congresso Internacional da Diversidade do Semiárido, 1, 2016, Campina Grande. Anais... Campina Grande: Editora Realize, 2016b.

BELLEN, H. M. Indicadores de Sustentabilidade: Uma análise comparativa. 2 ed. Rio de Janeiro: Editora FGV, 2006.

\section{POLÊM!CA $\mid$ LABORE}

Polêmica - Revista Eletrônica da Uerj - Rua São Francisco Xavier, 524, $1^{\circ}$ andar bloco D, sl.1001 • Tels.: +55 21 2334-4088/4087 • http://www.e-publicacoes.uerj.br/index.php/polemica/index http://www.labore.uerj.br • laboreuerj@yahoo.com.br 
BENINCÁ, M. C; OLIVEIRA, R. M; LEAL, C. R. A. A. A Relação Campo/Cidade Associada à Evasão de Jovens Rurais de Assentamentos do Sudoeste de Goiás. In: Encontro Nacional de Geografia Agrária, 11, 2012, Uberlândia. Anais... Uberlândia: Universidade Federal de Uberlândia, 2012.

BEZERRA, G. J; SCHLINDWEIN, M. M. Agricultura Familiar como Geração de Renda e Desenvolvimento Local: Uma Análise Para Dourados, MS, Brasil. Interações, Campo Grande, v. 18, n. 1, p. 3-15, jan./mar. 2017.

BRASIL. Código Florestal. Lei n 12.651 de 25 de maio de 2012. Dispõe sobre a proteção da vegetação nativa. Diário Oficial da União, Brasília, DF, 28 maio 2012.

Ministério da Agricultura, Pecuária e Abastecimento. Agricultura de Precisão. Brasília: MAPA, 2013.

2017.

Ministério do Meio Ambiente. Atlas irrigação: uso da água na agricultura irrigada. Brasília: ANA,

CASTRO, C. N. Desafios da Agricultura Familiar: O Caso da Assistência Técnica e Extensão Rural. Boletim

Regional, Urbano e Ambiental, v. 12, p. 49-59, jul./dez. 2015.

CAValCanti, N. B. et al. Fontes de Renda dos Pequenos Agricultores no Semi-Árido do Nordeste Brasileiro. Petrolina - PE: Embrapa, 2000.

COLMENAREZ, Y. C. et al. Uso do Manejo Integrado de Pragas e Controle Biológico pelos Agricultores na América Latina e no Caribe: Desafios e Oportunidades. In: HALFELD, V. B. de A. Defensivos agrícolas naturais: uso e perspectivas. Brasília: Embrapa, 2017. p. 802-853.

CPRM - Serviço Geológico do Brasil. Projeto cadastro de fontes de abastecimento por água subterrânea Estado De Paraíba: Diagnóstico do município de São José De Piranhas. Recife: CPRM/PRODEEM, 2005.

DEPONTI, C. M. Indicadores para avaliação da sustentabilidade em contextos de desenvolvimento rural local. 2002. 155 f. Monografia (Especialização em Desenvolvimento Rural e Agroecologia) - Universidade Federal do Rio Grande do Sul, Porto Alegre - RS, 2002.

FEITOSA, A. A. F. M. A. et al. A Transposição do Rio São Francisco na Paraíba: Uma Intervenção Proativa e os Desafios à Sustentabilidade. In: Congresso Brasileiro de Gestão Ambiental e Sustentabilidade, 4, 2016, João Pessoa. Anais... João Pessoa: Congestas, 2016.

FILHO, A. F. O. et al. Eficiência agronômica e biológica nos consórcios da mamoneira com feijão-caupi ou milho. Revista Ciência Agronômica, Fortaleza, v. 47, n. 4, p. 729-736, out./dez. 2016.

FINATO, J. et al. A Importância da Utilização da Adubação Orgânica na Agricultura. Revista Destaques Acadêmicos, v. 5, n. 4, 2013.

KAMIYAMA, A. Agricultura Sustentável. São Paulo: SMA, 2011.

KLEIN, M. A; ROSA, M. B. Adequação de Propriedades de Agricultores Familiares à Legislação Ambiental: A Educação Ambiental Como Mitigadora do Processo. Revista Eletrônica em Gestão, Educação e Tecnologia Ambiental, v. 4, n. 4, p. 453-468, 2011.

NOGUEIRA, M. A. F. S; SILVA G. G; GARCIA, M. S. Aproveitamento de Resíduos Sólidos da Agricultura Familiar no Assentamento Rural Lagoa Grande em Dourados - MS: Um Estudo de Caso. In: Primeiro Seminário de Integração e Desenvolvimento Regional, 2013, Ponta Porã - MS. Anais... Ponta Porã - MS, 2013.

OLIVEIRA, A. F. S. A Sustentabilidade da Agricultura Orgânica Familiar dos Produtores Associados à APOI (Associação de Produtores Orgânicos da Ibiapara - CE). 2007. 97 f. Dissertação (Mestrado em Desenvolvimento e Meio Ambiente) - Universidade Federal do Ceará, Fortaleza - PB, 2007.

\section{POLÊM!CA $\mid$ LABORE}

Polêmica - Revista Eletrônica da Uerj - Rua São Francisco Xavier, 524, $1^{\circ}$ andar bloco D, sl.1001 • Tels.: +55 21 2334-4088 / 4087 • http://www.e-publicacoes.uerj.br/index.php/polemica/index http://www.labore.uerj.br • laboreuerj@yahoo.com.br 
OLIVEIRA, N. D. A. et al. Práticas Produtivas da Agricultura Familiar: Um Estudo no Município de Espigão D’oeste (Ro). In: Encontro Nacional de Engenharia de Produção, 35, 2015, Fortaleza - CE. Anais... Fortaleza CE, 2015 .

OLIVEIRA, P. A. et al. Análise dos Custos de Produção para o Cultivo da Soja em Cenários Distintos de Produtividade e Preço no Interior Paulista. Revista do Agronegócio, v. 5, n. esp., p. 58-66, dez. 2016.

PATERNIANI, E. Agricultura sustentável nos trópicos. Estudos Avançados, v. 15, n. 43, p. 303-326, 2001.

PHILIPPI JR, A.; MALHEIROS, T. F. Indicadores de Sustentabilidade e Gestão Ambiental. Barueri: Manoele, 2013.

PRADO, R. B; TURETTA, A. P. D; ANDRADE, A. G. Manejo e Conservação do solo e da água no contexto das mudanças ambientais. Rio de Janeiro: Embrapa Solos, 2010.

REBOUÇAS, M. A; LIMA, V. L. A. Caracterização Socioeconômica dos Agricultores Familiares Produtores e Não Produtores de Mamão Irrigado na Agrovila Canudos, Ceará Mirim (Rn). Holos, Natal, ano 29, v. 2, p. 7995, 2013.

SANTOS, J. G. A Sustentabilidade da Agricultura Orgânica Familiar dos Produtores Vinculados a Associação de Desenvolvimento Econômico, Social e Comunitário (ADESC) de Lagoa Seca - PB. In: Encontro Nacional da Anppas, 5, 2010, Florianópolis - SC. Anais... Florianópolis, 2010.

SASSI, C. R. Proposta de Política de Assistência Técnica Agrícola: Um Desafio a Técnicos e Agricultores. Publicátio UEPG, v. 17, n. 2, p. 119-129, 2011.

SILVA, E. L.; MENEZES, E. M. Metodologia da pesquisa e elaboração de dissertação. 4 ed. Florianópolis: UFSC, 2005.

SILVA, M. R. Indicadores Propostos na Literatura Nacional para Avaliação de Sustentabilidade na Agricultura Familiar. Revista Monografias Ambientais, Santa Maria, v. 15, n. 1, p. 37-52, jan./abr. 2016.

SILVA, V. R. da; SILVA, M. M. da; PEREIRA, M. C. de B. Pluralidade e sustentabilidade em comunidades rurais do Semiárido nordestino. Desenvolvimento e Meio Ambiente, v. 35, p. 349-366, dez. 2015.

TONICASSO, H. R. et al. Agricultura Familiar e Associativismo Rural - O Caso Associação Harmonia de Agricultura Familiar de Mato Grosso do Sul e a Sua Sustentabilidade. Informe Gepec, v. 12, n. 2, jul./dez. 2007.

UNESCO. Década da Educação das Nações Unidas para um Desenvolvimento Sustentável, 2005-2014: documento final do esquema internacional de implementação. Brasília: UNESCO, 2005.

UZÊDA, M. C. O desafio da agricultura sustentável: alternativas viáveis para o Sul da Bahia. Ilhéus: Editora da UESC, 2004.

VARGAS, L. D. Políticas públicas e diversidade na Agricultura familiar: um estudo do Pronaf em Cachoeira do Sul/RS. 2012. 140 f. Tese (Dissertação em Extensão Rural) - Universidade Federal de Santa Maria, Santa Maria-RS, 2012.

VIEIRA, T. T. Adaptações em Implementos Agrícolas de Tração Animal. 2014. Monografia (Agroecologia) - Universidade Estadual da Paraíba, Lagoa Seca - PB, 2014.

ZAGO, N. Migração rural-urbana, juventude e ensino superior. Revista Brasileira de Educação, v. 21, n. 64, p. 61-78, 2016.

Recebido em: 01/04/2019.

\section{POLÊM!CA $\mid$ LABORE}

Polêmica - Revista Eletrônica da Uerj - Rua São Francisco Xavier, 524, $1^{\circ}$ andar bloco D, sl.1001 • Tels.: +55 21 2334-4088 / 4087 • http://www.e-publicacoes.uerj.br/index.php/polemica/index http://www.labore.uerj.br • laboreuerj@yahoo.com.br 
Aceito em: 30/05/2019.

\section{POLÊM!CA $\mid$ LABORE}

Polêmica - Revista Eletrônica da Uerj - Rua São Francisco Xavier, 524, $1^{\circ}$ andar bloco D, sl.1001 • Tels.: +55 21 2334-4088 / 4087 • http://www.e-publicacoes.uerj.br/index.php/polemica/index http://www.labore.uerj.br • laboreuerj@yahoo.com.br 